\title{
Canine Vector-Borne Diseases of Working Dogs of the Sri Lanka Air Force, Free-Roaming, and Privately-Owned Dogs
}

Rupika Subashini Rajakaruna ( $\sim$ rupikar@pdn.ac.lk)

University of Peradeniya https://orcid.org/0000-0001-7939-947X

PS Jayathilake

SLAF: Sri Lanka Air Force

HSU Wijerathna

Animalia AS

ADS Fernando

Government Veterinary Hospital, Wennappuwa

KMH Ginarathne

Sri Lanka Air Force

NGRK Naullage

SLAF: Sri Lanka Air Force

SNS Silva

SLAF: Sri Lanka Air Force

K Thananjayan

Sri Lanka Air Force

LKHRT Amarasiri

Sri Lanka Air Force

NPK Jayasundara

University of Peradeniya Faculty of Veterinary Medicine and Animal Science

MCK Mallawa

University of Peradeniya Faculty of Veterinary Medicine and Animal Science

A Dangolla

University of Peradeniya Faculty of Veterinary Medicine and Animal Science

\section{Research Article}

Keywords: dogs, hemoparasites, asymptomatic cases

Posted Date: August 16th, 2021

DOI: https://doi.org/10.21203/rs.3.rs-812331/v1

License: (c) (i) This work is licensed under a Creative Commons Attribution 4.0 International License. Read Full License 


\section{Abstract \\ Background}

Canine vector-borne diseases (CVBDs) are a significant health problem among dogs globally. The veterinary records show that the military working dogs of Sri Lanka die early at an average age of six years and CVBDs have been listed as one of the speculated causes. This study examined CVBDs in the working dogs of the Sri Lanka Air Force (SLAF) together with free-roaming and privately-owned dogs living close to the SLAF establishments and country-wide.

\section{Methods}

Blood samples were collected from the cephalic vein for a three year period, from July 2016 to July 2019. Giemsa stained thin blood smears were observed under light microscopy.

\section{Results}

A total of 668 dogs were sampled, of which 169 were infected (25.3\%) with hemoparasites. The prevalence of infections among the SLAF working dogs (22.5\%), free-roaming (26.3\%), or privately-owned (26.2\%) dogs did not differ significantly (Chi-square test, $p>0.05)$. A large number of infected dogs were asymptomatic (57.4\%), which was significantly higher in free-roaming dogs $(96.3 \%)$ compared to the SLAF $(41.1 \%)$ and privately-owned dogs $(38.2 \% ; p<0.0001)$ but not between SLAF dogs and privately-owned dogs $\left(\chi^{2}=0.005, p>0.938\right)$. Seven hemoparasites were identified: Babesia gibsoni, $B$. canis, Ehrlichia canis, Anaplasma platys, Leishmania sp., Hepatozoon canis, and microfilariae. The most common infection was B. gibsoni (13.8\%) followed by E. canis (9.9\%) and A. platys (4.3\%). There was no difference in the prevalence of $B$. gibsoni in the three categories of dogs $\left(\chi^{2}=2.61, p=0.10\right)$. Leishmania and $H$. canis were always presented as single infections, while microfilaria as mixed infections.

\section{Conclusions}

Even though the SLAF dogs are thoroughly quarantined before introducing them to the military units, the infection prevalence was similar compared to other dog categories. They have likely acquired the infections through ticks and other arthropod vectors. This is the first comprehensive and comparative island-wide study of dog CVBDs of Sri Lanka, especially the military dogs at the SLAF. It highlights that most infected dogs, especially the free-roaming ones, did not show clinical signs. Although it is speculated that they may act as reservoirs of infection, asymptomatic dogs' ability to spread these CVBDS should be investigated.

\section{Background}

Canine vector-borne diseases (CVBDs) represent a wide range of infectious diseases of major significance for canine health globally, especially in tropical and subtropical countries. The etiology of CVBDs involves protozoans, helminths, bacteria, and viruses, including Anaplasma, Babesia, Ehrlichia, Hepatozooan, Dirofilaria, Trypanosoma, Borrelia, Leishmania, Theileria, Mycoplasma, and Rickettsia. These are transmitted through different arthropod vectors like ticks, lice, fleas, mosquitoes, sand flies, tabanid flies, and triatomines. Clinical manifestation of CVBDs can vary from asymptomatic cases to severe health implications depending on the pathogenicity of the causative agent and the presence of co-infections complicating the diagnosis and host immunity and also the environmental factors [1-4].

Many CVBDs have been reported in dogs in Sri Lanka; these include Babesia gibsoni, Babesia canis [5-7], Ehrlichia.[6,8], Anaplasma platys [9], Hepatozoon [6,10], microfilaria belonging to Dirofilaria repens, Wuchereria and Brugia [11], 
Trypanasoma evansi [12] and Leishmania [13]. Serological evidence of exposure of dogs to rickettsial infections identified Rickettsia conorii, Rickettsia typhi, and Orientia tsutsugamushi [14]. Co-infection of several species of Anaplasma, Babesia, Ehrlichia, Rickettsia, and Hepatozoon are common among the dogs brought to the veterinary care facilities [15]. However, detailed data such as geographic distribution of the disease, epidemiology, vectors of CVBDs are not available or scant or outdated. Consequently, the development of new and endemic foci of CVBDs in non-endemic areas could occur in the absence of efficient veterinary and public health surveillance networks, possibly resulting in a rapid spread of the infection among the dog populations.

Dogs infected with the CVBDs may show varying clinical presentation, pathogenicity, and response to therapy [16]. As early as 1953, Seneviratna [17] studied piroplasmosis in dogs in Sri Lanka, describing B. gibsoni, the small canine Babesia infections in dogs [18], its treatment [19], and pathology [20]. Clinical determinants of the infection include virulence of the agent, age, gender, and the dog's immune status. Clinical presentation and pathogenicity of the disease show variation among the pedigreed and stray dogs. Mostly young adults of pedigreed dog breeds like German shepherds, Dobermann and Pomeranians show the highest susceptibility, while Rottweilers, Labradors, Boxers, and crossbred dogs of any age are more susceptible for babesiosis and ehrlichiosis than other breeds [15]. However, non-pedigree, mixed breeds, and stray dogs show more resistance and tolerance to these infections in most probably due to diverse ancestry and good genetic diversity [15]. Most of these CVBDs represent a substantial diagnostic challenge for veterinarians in that clinical signs are often absent, diffuse, and overlapping. Besides, co-infections with two or more pathogens enhance this problem further.

Currently, CVBDs have been identified as a significant health concern among the military working dogs (Personal communication with the military kennel veterinarian, Katunayake). There are about 500 working dogs in the Sri Lanka Army, Navy, Air Force and the Police. Most of these dogs are imported from various countries, largely from the UK, Germany, and the Netherlands, and some are locally bred (Personal communication with the veterinarians in the military and Police). The working dogs die early, and the average age at death is 6.1 years of those in the Sri Lanka Police [21]. Moreover, 75\% of the dogs belong to the Sri Lanka Air Force (SLAF), and Army have died, presumably due to tick-borne infections, although suspected, these have not been confirmed or properly diagnosed (personal communication with the Squadron leader and the Manager of Animal Husbandry Project at the SLAF, Katunayake). Although there is a proper quarantine and screening process for all the dogs before introducing them to the military unit, they may however, acquire the diseases through the arthropod vectors once they are brought to the country. There is an urgent need to provide baseline data on the types of infections and prevalence of these diseases in dogs in military kennels so the future trends can be monitored. This study was conducted to determine the occurrence of CVBDs in the military working dogs in the SLAF and free-roaming community dogs, and privately-owned dogs.

\section{Methods}

\section{Study animals}

Sri Lanka has an estimated population of seven million dogs with a density of 100 dogs $/ \mathrm{km}^{2}$ [22]. These dogs can be categorised as 1) Privately-owned dogs that do not mingle with free-roaming stray and other community dogs. These dogs stay inside the house or enclosed garden most of the time and are taken out only for defaecation/ urination and daily exercise. They are routinely vaccinated, dewormed, and taken to a veterinary hospital or clinic regularly. 2) owned dogs that mingle with free-roaming and community dogs. They are mostly vaccinated and dewormed but may or may not be routinely and taken to the hospital during sickness or injury 3) community dogs with no specific owner but the household members in the vicinity feed them. They may be vaccinated through mobile clinics but not dewormed or taken to a hospital unless on rare occasions 4) free-roaming stray dogs that do not have an owner and feed on garbage, sometimes hunt other animals and are not vaccinated or given any veterinary care during acute sickness or severe injury or very rarely for vaccination. Free-roaming strays are shy of people and are considered the true stray dogs having a higher possibility and closer contact 
with wild animals. For this study, dog categories 1 and 2 were considered as privately-owned dogs and categories 3 and 4 were considered as free-roaming dogs in data presentation and analysis.

Sri Lanka has dogs belonging to many breeds. Some of the owned dogs are purebred pedigreed dogs. However, most are mongrels, crossbred with different breeds, or crossbred with the local Sinhala hound or Sinhalese hound belonging to the species Sinhala sunakaya which is found in Sri Lanka and parts of India [23]; are called mongrels from here onwards). Besides, there are military working dogs belonging to the SLAF, Air Force, Navy, and Police. These military dogs are mostly imported, and a few are bred locally. Among the 286 military dogs in the SLAF, Air Force, Navy, and the SLAF dogs are distributed in a few locations all over the country, with the main kennel located at Katunayaka. Some of them were brought from the UK and Germany five years ago, and some were locally purchased dogs. The SLAF also has its dog breeding station at Diyathalawa. These military dogs are used in various tasks, including explosive detection, tracking, guard dogs, life-saving, dog shows, and security, demining, and narcotic detection.

\section{Study sites and Sample collection}

Blood samples were collected from the cephalic vein of the dogs at the three SLAF establishments, healthy dogs close to these establishments (both free-roaming and privately-owned) and an island-wide collection of blood samples from dogs was brought to the veterinary care facility (both free-roaming and privately-owned) with the support from the field veterinarians. The required minimum sample size was calculated using the Creative Research Systems survey software (http://www.surveysystem. com/ sscalc.htm), considering a 50\% expected hemoparasite prevalence, with an acceptable $10 \%$ variation at $95 \%$ confidence interval level. Information on whether the dogs had clinical signs suggestive of hemoparasites was also collected for an individual dog from either the respective handler, owner, or from a known party for stray dogs. Samples were taken from the following categories of dogs: a) SLAF with signs b) SLAF without signs c) dog categories 1-4 close living proximity to the SLAF d) dog categories 1-4 brought to the veterinary clinic with signs e) dog categories 1-4 brought to the clinic without signs. Samples were collected from July 2016 to July 2019.

\section{Giemsa stained thin blood smears}

Thin blood smears were prepared, air dried, stained with Giemsa, and examined under the light microscope on oil immersion (at $1000 \mathrm{X}$ magnification) for hemoparasites.

\section{Data analysis and ethical clearance}

Results were presented as proportions and percentages in tables, while a chi-square test or a Fisher's Exact test at $5 \%$ significance was performed at appropriate degrees of freedom when required to compare categories.

Ethical clearance for the study protocols was obtained from the Ethical Review Committee at the Postgraduate Institute of Science, University of Peradeniya, Sri Lanka.

\section{Results}

\section{Study animals}

Blood samples from dogs were collected from 18 districts (out of 25) in Sri Lanka (Figure 1). A total of 668 dogs were sampled, comprising of 173 from the three SLAF establishments, 205 free-roaming dogs (115 healthy dogs living close to the SLAF establishments and 90 from veterinary clinics island-wide), and 290 privately-owned dogs (90 healthy dogs living close to the SLAF and 200 from veterinary clinics island-wide). All the SLAF dogs were purebred while the free-roaming dogs were all mongrels and the privately-owned dogs were a mixture of either purebred or mongrel or mixed breeds. Military working dogs at the SLAF belonged to seven breeds: German Shepherd, Labrador Retriever, Doberman, English Springer spaniel, Rhodesian Ridgeback, and Rottweiler (Table 1). They were either imported or the parents were imported, 
but some were locally bred (Table 1). There were 271 (40.8\%) male dogs and 397 (59.4\%) female dogs comprising of 560 (83.8\%) adults and 108 (16.2\%) puppies (Table 2).

\section{Prevalence and types of blood haemoparasitic infections}

Overall, 169 dogs (25.3\%; Table 2) were infected with one or more haemoparasites. Out of the infected dogs, 144 (85.2\%) were single infections, while 25 dogs were presented as mixed infections (14.8\%). The prevalence of infection in the dogs from the SLAF, free-roaming and privately-owned dogs was $25.5 \%, 26.3 \%$ and $22.8 \%$, respectively. There was no significant difference in the overall prevalence of infection among the three dog categories (Chi-square test $\chi^{2}=0.938, p>0.05$ ). Moreover, there was no sex predilection showing a difference in the prevalence of infection between male (9.6\%) and female (15.7\%; Table 2) dogs (Chi-square test, $p>0.05$ ).

Seven types of haemoparasites: Babesia. gibsoni, Babesia canis, Ehrlichia canis, Hepatozoon canis, Leishmaia sp., Anaplasma platys and microfilariae were recorded from microscopic examination of thin blood smears (Table 3). Babesiosis was the most common disease among the dogs island-wide (14.1\%), caused by two parasites: B. gibsoni (13.8\%) and B. canis (0.1\%), contributing a significantly higher number by $B$. gibsoni (Fisher's Exact test, $\chi^{2}=80.8119, \mathrm{p}$ $<0.0001)$. Overall, the second most common infection was E. canis (9.9\%) followed by A. platys (4.3\%). This distribution was similar in the dogs at the SLAF where B. gibsoni and E. canis were the most common (8.7\%) followed by $A$. platys (4.6\%). There was no difference in the prevalence of $B$. gibsoni in SLAF dogs (8.7\%) and other dogs $\left(15.6 \% ; \chi^{2}=2.61\right.$, $p=0.10)$ however, the prevalence of $A$. platys was higher in SLAF dogs $(6.4 \%)$ compared to the other dogs $\left(3.6 \% ; \chi^{2}=7.274\right.$, $\mathrm{p}=0.007$ ). Babesia canis was found only in the privately-owned dog in Colombo (Sky Pet hospital, Colombo). The lowest prevalence of mixed infections was reported in the SLAF dogs (1.8\%) and highest among the free-roaming dogs (5.4\%) but the difference was not significant (Fisher's Exact test, $\left.\chi^{2}=0.0982, p>0.05\right)$.

Leishmania sp. and $H$. canis occurred only as single infections. Other infections occurred as mixed infections of two or three parasites of various combinations (Table 3). Microfilaria always occurred as mixed infections. The most common mixed infection was E. canis and A. platys (13 dogs) followed by B. gibsoni and E. canis (7 dogs). Even though mixed infections were rare among the SLAF dogs, one dog had B. canis, $A$. platys and microfilariae (Table 2). The least common single infection was $H$. canis reported from one privately-owned dog in Borella, Colombo while Leishmania was found only in free-roaming dogs in Katunayake. Microfilariae were always found as mixed infections (4 dogs; Table 2). All the dog categories harboured B. gibsoni, E. canis, A. platys and microfilariae. Most free-roaming dogs from clinics did not have hemoparasites except for B. gibsoni and E. canis infections.

\section{Geographic distribution of canine hemoparasites}

The number of dogs and the types of infections in the three SLAF establishments were different (Table 4). Still, there was no difference in the prevalence of disease among the dogs in the three SLAF locations (Fisher's Exact Test, $p>0.05$ ). Of the 18 districts, the Gampaha District had the highest prevalence (66.7\%) followed by the Anuradhapura District (53.3\%) and Ratnapura District had the lowest prevalence (10.0\%) followed by Trincomalee (13.3\%) of canine hemoparasites among the free-roaming and privately-owned dogs (Table 5). In all the other districts, the prevalence was within $20-40 \%$.

\section{Distribution of infection among dog breeds}

Breeds that were mostly infected in the SLAF were German Shepherd (36.1\%), English Spaniel and Labrador Retrievers (25.1\%), while among the privately-owned dogs, Beagles (100\%), Shih tzu (100\%), and Dachshund (83.3\%) were infected (Table 6).

\section{Clinical signs and asymptomatic cases}


Haemoparasites were found both in dogs with clinical signs and without clinical signs. Anorexia, lethargy, fever, pale mucosa, dark urine, epistaxis, skin bleeding on ventral abdomen, emaciation were the most common clinical signs (Table 7). Besides, there were dogs showing clinical signs, but the blood smears were microscopically negative for hemoparasites (SLAF dogs $23.3 \%$ and privately-owned dogs $11.3 \%$ ). The percentages of infected dogs with clinical signs and without clinical signs were comparable in SLAF (without signs $41.1 \%$ with signs $58.9 \%$ ) and privately-owned dogs (without signs $38.2 \%$ with signs $61.8 \%$ ) having more individuals with clinical signs. However, among the infected free-roaming dogs, a large number (96.3\%) did not show signs while only 3.7\% showed signs and this was significantly higher compared to SLAF and privately-owned dogs (Chi-square test, $p<0.00001$ ) but there was no difference between SLAF dogs and privatelyowned dogs $\left(\chi^{2}=0.005, p>0.938\right)$. All the dogs at the SLAF with mixed infections showed clinical signs, while none of the free-roaming dogs with mixed infections showed any signs (Table 8). The SLAF dogs with no clinical signs rarely had parasites compared to other categories and if they do show, it is mostly due to B. gibsoni followed by E. canis and $A$. platys. Among the breeds, Labrador Retrievers were mostly showing symptoms which include anorexia, lethargy, fever, pale mucosa, dark urine, epistaxis, skin bleeding on ventral abdomen, and emaciation (Table 7). Among the free-roaming dogs, only two from Katunayake were clinically ill, showing signs of skin disease. Both these dogs were infected with Leishmania sp. This parasite was not found by any other dog in the entire sample.

\section{Discussion}

This study reports the first comprehensive, island-wide investigation of CVBDs comparatively among the privately-owned and free-roaming community dogs and the military working dogs of the SLAF. Even though all the parasites species have been previously recorded in Sri Lanka, those studies are either confined to one or a few sites or focused on particular species of parasites. Blood parasites of military working dogs in SLAF have not been studied before. One-fourth of the dogs $(25.3 \%)$ examined were infected with haemoparasites, mostly as single infections and some mixed infections. There was no difference in the prevalence of infection among the three dog categories from the SLAF, free-roaming and privatelyowned dogs. A study with 2,104 dogs comprising a stray dog population in Asam, India and a hospital population including privately-owned pet dogs and working dogs of the Central Parliamentary Forces reported $57.31 \%$ infected with hemoparasites comprising $58.03 \%$ in pets, $54.54 \%$ in the working dogs and $63.64 \%$ in stray dogs [24]. Similarly, there is no difference of infection among the three dog categories, although the percentages of infected dogs are higher than those reported in the present study.

Among the infected dogs, a significantly higher number of free-roaming dogs were asymptomatic compared to the other two dog categories (SLAF and Privately-owned) but there was no difference in the asymptomatic cases between the SLAF dogs and privately-owned dogs. This is anticipated since better natural resistance against hemoparasites in stray dogs compared to privately-owned dogs or pure breeds of dogs has been established long ago [25]. The absence of clinical signs indicates that these dogs may be chronically or subclinically infected with these haemoparasites or as Dantas-Torres and Ontranto (2014) [26] point out, they may be having clinical pathological abnormalities and organ dysfunctions. Although chronic infections may not pose an immediate threat to the animals, these dogs do remain possible reservoirs for infections, stressful conditions, concurrent illnesses and parturition may precipitate clinical signs in chronically infected animals [27]. The free-roaming dogs are sub-clinically infected and may provide a continuous source of infection for these pedigree dogs. Arthropod vectors can transmit these infections from the free-roaming dogs to owned dogs which are mostly pedigreed dogs. Pedigree dogs are selectively bred to conform to the aesthetic value of the dog rather than its health and therefore frequently suffer from the effects of inbreeding as the gene pool available is highly limited. Studies have shown that such breeding practices could have increased the expression of inherited defects and thus compromised the health and welfare of many breeds [28-31]. The reduced heterozygosity of a highly inbred population can contribute to the frequency of occurrence of inherited disease in the population [30,32]. The top 50 most popular breeds of pedigree dogs in the UK are predisposed to 312 inherited disorders, with German shepherd dogs and Golden retrievers associated with the most significant number of ailments [33]. Many vector-borne bacteria and protozoa in healthy hunting dogs from Central Italy 
and confirmed that dogs infected by these pathogens often develop asymptomatic or subclinical forms [34]. Another study in Turkey [35] reported a lower percentage of $5.4 \%$ out of 757 asymptomatic domestic dogs being infected with vector-borne rickettsia and protozoans. The presence of hemoparasites in asymptomatic dogs is relevant from an epidemiological point of view as the transmission potential of symptomatic and asymptomatic dogs can vary depending on the parasite species. For example, some studies have shown that asymptomatic dogs are unable to infect vectors with Leishmania [36,37], others demonstrate that transmission occurs in similar proportion as that for oligosymptomatic animals, but to a lesser extent than for symptomatic dogs [38-43]. It is important to investigate whether these asymptomatic dogs serve as reservoirs. However, Dantas-Torres and Otranto [26]argue that although the term "asymptomatic" is still used in the international literature, it is falling into disuse because the classification of dogs as asymptomatic, oligosymptomatic, and polysymptomatic based only on physical examination [44] and therefore is of limited value, as it does not consider clinical pathological abnormalities and also disregards dogs presenting organ dysfunction but with-out apparent clinical manifestations [45] especially when the dog is infected by Leishmania infantum.

The present study reported seven hemoparasites: Babesia gibsoni, Babesia cani, Ehrlichia canis, Hepatozoon canis, Leishmaia sp., Anaplasma platys and microfilariae. Out of these, B. gibsoni, E. canis and A. platys were recorded in all three dog categories. Among these, B. gibsoni was the most prevalent canine hemoparasite island-wide (13.8\%). Only one case of $B$. canis was reported from a privately-owned dog. It is interesting to study why $B$. canis, which is clinically more important due to its ability to cause lethal nervous signs in dogs, is rare when the vector is the same as $B$ gibsoni. There was no difference in the prevalence of $B$. gibsoni among the three dog categories: SLAF, free-roaming and privately-owned dogs. Globally, babesiosis is a common vector-borne disease among domestic and wild canines [46]. A recent study from the Anuradhapura district in Sri Lanka reported B. gibsoni and B. canis (with a prevalence of $15.0 \%$ and $1.3 \%$, respectively) in addition to mixed infections in three Divisional Secretariat Divisions (DSDs): Rambewa, Tirappane, and Galenbidunuwewa [6]. A more recent study investigated canine babesiosis in dogs brought to the Veterinary Teaching Hospital in the University of Peradeniya and showed a high prevalence of B. gibsoni (78.6\%) in the Kandy district [7]. The study conducted in stray dog population in Asam, India also reported B. gibsoni as the highest prevalent infection with an infection rate of $47.16 \%$ in hospital dogs and $47.72 \%$ in stray dogs [24]. In the present study, all the free-roaming dogs (100\%) that were smear-positive for babesiosis (31dogs) were asymptomatic, while $46.7 \%$ of the SLAF dogs and $27.5 \%$ of the privately-owned dogs were asymptomatic. Asymptomatic babesiosis has been reported elsewhere with a prevalence of $3.42 \%$ (29 of 848 ) cases of asymptomatic dogs in Croatia [47]. The prevalence of babesiosis could be higher in these dogs as Ranatunga et al. [7] reported that $33.3 \%$ of blood smear negative dogs were PCR positive for Babesia DNA.

Ehrlichiosis or infection with Ehrlichia canis was the second most prevalent canine hemoparasite, and its prevalence among the SLAF dogs was as same as that of $B$. gibsoni infection (15 dogs). Most were asymptomatic. None of the smearpositive, free-roaming dogs (12) showed any signs, while $62.5 \%$ SLAF dogs and $50 \%$ privately-owned dogs were also asymptomatic. Infection with E. canis in dogs may result in acute disease, chronic disease or remain clinically silent [48]. Moreover, due to the non-specific and variable symptoms of ehrlichiosis, dogs are often misdiagnosed or diagnosed past the point of recovery and such cases can be fatal [49]. A higher prevalence of E. canis infections (56.1\%) [6] compared to the previously reported prevalence of $14 \%$ in dogs in the Western Province [50]. A previous study carried out in Sri Lanka observed E. canis in imported dogs [51]. In Asam, India, dogs infected with E. canis was much less (<3\%), comparatively [24]. Ehrlichia canis has a worldwide distribution, and dogs and other canids are the natural hosts. It is generally not considered as a zoonotic agent, but some cases of human infection have been reported in Venezuela [52].

Anaplasmosis or Anaplasma platys infection was also reported from all three dog categories with a higher prevalence among the SLAF dogs (6.4\%) compared to other dog categories. The first record of A. paltys (formerly known as Ehrlichia canis) in Sri Lanka was in 2005 from Colombo used buffy coat analysis and confirmation by PCR [5]. This study reported $18 \%$ owned dogs and $12 \%$ stray infected while $75 \%$ with no clinical signs. The study carried out in three DSDs in the Anuradhpura district didn't report A. platys in their sample [6]. Anaplasma platys is also more common (8.49\%) among the 
working dogs in Asam, India (Bhattacharjee and Sarmah, 2013). Anaplasmosis is an emerging infectious diseases affecting dogs in many parts of the world and can be manifested as acute or non-clinical infections [53].

Leishmania was found only in two free-roaming dogs as a single infection with a prevalence of $0.9 \%$. This is consistent with the results of a recent study examining 114 stray dogs in Sri Lanka; only one dog $(0.9 \%)$ having detectable antiLeishmania sp. antibodies [54]. Another study examined 151 dogs, of which two showing Leishmania amastigotes in Giemsa-stained smears (prevalence 1.3\%), one in the skin and one in peripheral blood [13]. These studies show that the prevalence of canine leishmaniasis may not be a widespread CVDB. However, its zoonotic potential has been highlighted $[13,54]$. Human leishmaniasis is an emerging infection caused by Leishmania donovani which is traditionally considered a visceralizing anthroponotic species but causes cutaneous leishmaniasis in Sri Lanka [55]. In the present study both infected dogs showed clinical signs. Asymptomatic dogs, some even without skin parasitism, are competent in transmitting Leishmania to the vector, the sandfly [43]. However, some [26] argue that the term "asymptomatic" is of limited value because it does not consider clinical-pathological abnormalities and those with organ dysfunction [45] and recommend the LeishVet guidelines of $[56,57]$ for those who are involved in research in canine Leishmaniasis. In India, the presence of Leishmania has been attributed to domestication of dogs by tribes to protect them from untoward activities of wild animals [58]. Canine leishmaniosis due to L. infantum is enzootic in some countries, and it is an emerging zoonosis in endemic foci.

Only one privately-owned dog was infected with $\mathrm{H}$. canis. Acute hepatozoonosis in five dogs have been characterized by neurological symptoms, ataxia orparesis, emaciation and anaemia [10]. Recently, in Galenbindunuwewa, $H$. canis has been reported with B. gibsoni infections [6]. Hepatozoon canis is a common CVBD and has been reported from several parts in India [59] and also is distributed throughout the old world. Disease-associated with the infection is usually asymptomatic, while disease, when present, may range from subclinical and chronic, especially in the absence of concurrent infections, to severe and life-threatening [60].

Microfilaria was also found in all three dog categories but was always as mixed infections either with $B$. gibsoni in freeroaming and privately-owned dogs or with $B$. canis and $A$. platys in the SLAF dogs. Canine filariasis has been reported previously from Sri Lanka and the species identified include Dirofilaria repens, Brugia ceylonensis and Brugia malayi, and their geographic distribution and prevalence varied from 30 to $68.8 \%$ [11,61, 62]. Mallawarachchi et al. [11] anticipate that the actual rates of infections are even higher. However, the prevalence of microfilaria in the present study was $0.6 \%$ with only four dogs being infected. All the canine filaria worms recorded in Sri Lanka are zoonotic (see 11] and have the potential to cause disease in humans. In 2016, Sri Lanka received the WHO certification for the elimination of lymphatic filariasis or the bancroftian filariasis [63]; however, the emergence of zoonotic canine filariasis may endanger the filariasis-free status of the country due to the potential reservoirs for humans.

The pattern of infection of hemoparasites was similar in the SLAF dogs and the free-roaming dogs, island-wide. However, it varied in the privately-owned dogs. Socio-economic factors of the dog owners and their capability or willingness to afford to use methods to control ectoparasites contribute to the level of infection among the privately-owned dogs [64]. The SLAF veterinarians claim that there are a thorough quarantine and screening process for all the imported dogs, even to detect infections at subclinical levels before introducing them to the military units. It is highly likely that they have acquired the diseases through the tick vectors once they are brought to the country. Stray dogs may act as reservoirs of these diseases as there is a substantially high population of stray dogs found island-wide. As a strategy to suppress the spread of rabies, the Rabies Ordinance of 1893 allowed stray, free-roaming dogs to be seized and disposed of. However, in 2006 a presidential order was passed to implement a "no-kill policy" and with the lobbying of animal activists, a more humane approach of "catch-neuter-vaccinate-release" method (CNVR) was practiced. The statistics show a dramatic decline in reported cases of rabies, but these free-roaming dogs act as constant reservoirs of CVBDs by habouring the vectors of these infections.

Environmental changes have an effect on emerging parasitic diseases [65]. As Dantas Torres reviews in 2015, human developments affect the environment and the climate, which in turn have an effect on biodiversity and alter tick population 
dynamics and tick-borne pathogen transmission. The present study provides baseline data on the types of infections and prevalence of these diseases in dogs in military kennels, free-roaming, and privately-owned dogs in Sri Lanka. They can be used in future studies of disease dynamics, vectors of infections, seasonality, together with additional knowledge on ticks and other vectors, animals, pathogens, and their interactions with the whole ecosystem.

\section{Conclusions}

Haemoparasites can be diagnosed from clinical signs and microscopic examination of stained blood smears but has very limited sensitivity. In addition, in-clinic serology tests do not differentiate active infection from prior exposure; therefore, molecular techniques have become the preferred method for the detection of most canine vector-borne hemoparasites.

\section{Declarations}

\section{Acknowledgment}

Authors thank the personnel at the SLAF establishments, veterinary clinics and dog owners for their support in sample collection. Financial assistance was provided by the National Science Foundation (Grant no: RG/2019/BT/02).

\section{DECLARATION}

Ethics Approval - All the study protocols and objectives were approved by the Institutional Ethical Clearance Committee of postgraduate Institute of Peradeniya, Sri Lanka

Consent to Participate - Obtained.

Consent for publication - Not Applicable.

Funding - Financial assistance from the National Science Foundation Sri Lanka (Grant No. RG/2019/BT/01) and the National Research Council Sri Lanka (Grant No. 20-083)

Availability of Data and Material - All data are available in hard copies and soft copies with the principal investigator stored securely releasable upon any reasonable request

Conflicts of Interest - Authors declare that there is no conflict of interest

Code Availability - Not Applicable

Acknowledgements: Financial assistance from the National Science Foundation (Grant No. RG/2019/BT/01) and the National Research Council (Grant No. 20-083) Sri Lanka are acknowledged.

\section{Authors' contributions -}

P.S. Jayathilake (Conceptualization, data acquisition, curation and analysis, writing the manuscript),

R.S. Rajakaruna (conceptualization, methodology, editing manuscript, supervision, project administration)

A.D.S. Fernando; H.S.U. Wijerathna; K.M.H. Ginarathne; N.G.R.K. Naullage; S.N.S. Silva; K. Thananjayan; L.K.H.R.T. Amarasiri; N.P.K. Jayasundara; M.C.K. Mallawa (data acquisition, analysis, visualization, resources), \&

A. Dangolla (conceptualization, editing, supervision, project administration) 


\section{References}

1. Dantas-Torres, F. 2008. Canine vector-borne diseases in Brazil. Parasit. Vector 1, 25

2. Dantas-Torres, F. 2015. Climate change, biodiversity, ticks and tick-borne diseases: The butterfly effect. International J Parasitol: Parasit. Wildlife. 4:3 452-461.

3. Otranto, D., Dantas-Torres, F., Breitschwerdt, E.B. 2009. Managing canine vector-borne diseases of zoonotic concern: part one. Trends Parasitol. 25:157-163.

4. Day, M.J. 2011. One health: the importance of companion animal vector-borne diseases. Parasites \&vectors, 4, 1. https://doi.org/10.1186/1756-3305-4-49.

5. Bennett, S.R., Quinn, R.L., Teleford, S., Rich, D.S., Kulasekera, V., Obeysekera, N., Collure, J., Siriwardana, D., Kirihena, C.D., Fernando, G. 2005. The prevalence and significance of canine erlichiosis in Colombo, Sri Lanka. SL Vet J. 52, 1-8.

6. Weerathunga, D., Amarasinghe, A., Iddawela, D., Wickramasinghe, S. 2019. Prevalence of canine tick-borne haemoparasites in three Divisional Secretariat Divisions (Rambewa, Tirappane, and Galenbidunuwewa) in the Anuradhapura district, Sri Lanka. Sri Lankan J. Infect. Dis. 9,111-119.

7. Ranatunga, R.A.S., Dangolla, A., Sooriyapathirana, S.D.S.S. and Rajakaruna, R.S. 2020.Canine babesiosis: prevalence, intensity and molecular identification of Babesia species infecting dogs brought to the Veterinary Teaching Hospital, Peradeniya. Proc. 7th Postgraduate Institute of Science Research Congress.

8. MacGaughey, C.A., Seneviratne, P., Mahalingam, S. 1962. Rickettsiosis of dogs in Ceylon. Ceylon Vet. J. 10,82-87.

9. Jayathilake, P.S., Pinnagoda, P.P.H., Gunawardena, P.E., Ginarathne, K.M.H., Silva, I.D., Dissanayake, R.D.A., Wijeyawardena, N., Mallawa, M.R.C.K., Karunaratne, T.M.W., Dangolla, A., Rajakaruna, R.S. 2018. Emergence of a Thrombocytopenic disorder in a group of working dogs of Sri Lanka Air Force. Sri Lanka Vet. J. 85,13-15.

10. Atapattu, U.D., Dissanayake, D., Silva, I.D., Bulumulla, D., Neelwala, N., Wijekoon, T. 2017. Acute Hepatozoonosis caused by Hepatozooncanis in dogs in Sri Lanka. SL Vet. J. 64:9-12.

11. Mallawarachchi, C.H., Chandrasena, N.T.G.A., Wickramasinghe, S., Premaratna, R., Gunawardane, N.Y.I.S. 2018. A preliminary survey of filarial parasites in dogs and cats in Sri Lanka. PLoSONEe. 13, 1-11.

12. Dangolla, A., Wijesundara, D.L.R., Blair, D., Fernando, D.D., Wijesundera, K., Chathuranga, W.G.D., de Silva, W.A.P.P., Rajakaruna, R.S. 2020. Canine Trypanasomiasis in Sri Lanka: An emerging problem reported from three distinct geographical locations. Parasitol. Int. 77,1-5.

13. Nawaratna, S.S.K., Weilgama, D.J., Rajapaksha, K. 2009. Cutaneous leishmaniasis in Sri Lanka: A study of possible animal reservoirs. International J. Infect. Dis. 13,513-517

14. Nanayakkara, D.M., Rajapakse, R.P.V.J., Wickramasinghe, S.,Kularatne S.A.M. 2013. Serological Evidence for Exposure of Dogs to Rickettsia conorii, Rickettsia typhi, and Orientia tsutsugamushi in Sri Lanka. Vector-Borne Zoonot. Dis. 13,545-549.

15. Silva, I.D. 2016. Complex clinical presentation of Tick-borne diseases in dogs in Sri Lanka .Sri Lanka Vet. J. 63, 1-9.

16. Shaw, S.E., Day, M.J., Birtles, R.J., Breitschwerdt, E.B. 2001. Tick-borne infectious diseases of dogs. TrendsP a r a s i t o I. $17,74-80$

17. Seneviratna, P. 1953. Piroplaamosis of dogs in Ceylon.Ceylon Vet. J. 1, 95-98.

18. Seneviratna, P. 1965a. Studies of Babesia gibsoni infections of dogs in Ceylon.Ceylon Vet. J. 13, 107-110.

19. Seneviratna, P., Jayawickrama, S.D. 1961. Treatment of Babesin gibsoni infections in dogs with Spirotrypanhoeschst. Indian Vet. J. 38,465474.

20. Seneviratna, P. 1965b. The pathology of Babesia gibsoni (Patton, 1910) infection in the dog.Ceylon Vet. J. 13,107-110.

21. Jayathilake, R.G.I. 2020. Probable causes of death of working dogs at Department of Police, Sri Lanka, during 20092019.Master's thesis. University of Peradeniya 
22. Matter, H.C., Wandeler, A., Neuenschwander, B., Harishandra, L., Meslin, F. 2000. Study of the dog population and rabies control activities in the Mirigama area of Sri Lanka: Acta Trop. 75,95-101\

23. Deraniyagala, S. 1992. The Prehistory of Sri Lanka: An ecological perspective. Colombo: Department of Archaeological Survey, Govt. of Sri Lanka. ISBN 955-9159-00-3

24. Bhattacharjee, K., Sarmah, P.C. 2013. Prevalence of haemoparasites in pet, working and stray dogs of Assam and North-East India: A hospital based study. Vet. World 6, 874-878.

25. Jalali, M.H.R., Mosallanejad, B., Avizeh, R., Alborzi, A.R., Hamidinejat, H., Taghipour, R. 2013. Babesia infection in urban and rural dogs in Ahvz district, south west of Iran, Archiv.Razi Inst. 68, 37-42.

26. Dantas-Torres, F., Ontranto, D. 2014. When is an "asymptomatic" dog asymptomatic? Vet. Parasitol. 202:341-342.

27. Harrus, S., Waner, T., Bark.,Jongejan, F., Comelissen, A.C.A. 1999. Recent advances in determining the pathogenesis of canine monocyticehrlichiosis. J. Clin. Microbiol. 37, 2745-2749.

28. Ubbink, G.J., van de Broek, J., Hazewinkel, H.A., Rothuizen, J. 1998. Cluster analysis of the genetic heterogeneity and disease distributions in purebred dog. Vet Rec. 142,209-13.

29. Galibert, F., Andre, C. 2006. The dog genome. Genome Dynamics 2, 46-59.

30. Cruz, F., Vila, C., Webster, M.T., 2008. The legacy of domestication: accumulation of deleterious mutations in the dog genome. Mol. Biol. Evol. 25, 2331-2336.

31. Oberbauer, A.M., Belanger, J.M., Bellumori, T., Bannasch, D.L., Famula, T.R. 2015. Ten inherited disorders in purebred dogs by functional breed groupings. Canine Genet. Epidemiol. 2,1-11.

32. Meyers-Wallen, V.N. 2003. Ethics and genetic selection in purebred dogs.Reprod. Domest. Anim. 38, 73-76.

33. Summers, J.F., Diesel, G., Asher L., McGReevy, D., Collins, L.M. 2010 Inherited defects in pedigree dogs. Part 2: Disorders that are not related to breed standards. Vet. J. 183, 39-45.

34. Ebani, V.V., Fognani, G., Mugnaini, L. Fabrizio, B., Rocchigiani, G., Papini, R.A., Stefani, F., and Mancianti, F. 2015. Molecular detection of vector-borne bacteria and protozoa in healthy hunting dogs from Central Italy.Asian Pac. J. Trop. Biomed. 5,108-112.

35. Aktas, M., Özübek, S., Altay, K., Ipek, N., Balkaya, I., Utuk, A., Kırbas, A., Şimsek, S., Dumanlı, N. 2015. Molecular detection of tick-borne rickettsial and protozoan pathogens in domestic dogs from Turkey.Parasite Vector.8, 157.

.doi:10.1186/s13071-015-0763-z.

36. Travi, B.L., Tabares, C.J., Cadena, H., Ferro, C., Osório, Y. 2001. Canine visceral leishmaniasis in Colombia: relationship between clinical and parasitological status and infectivity for sand flies. Am. J. Trop. Med. Hyg. 64, 119-124.

37. Vercosa, B.L., Lemos, C.M., Mendonc, a, I.L., Silva, S.M., de Carvalho, S.M.,Goto, H., Costa, F.A., 2008. Transmission potential, skin inflammatory response and parasitism of symptomatic and asymptomatic dogs with visceral leishmaniasis. BMC Vet. Res. 4, 45.

38. Courtenay, O., Quinnell, R.J., Garcez, L.M., Shaw, J.J., Dye, C. 2002. Infectiousness in a cohort of Brazilian dogs: why culling fails to control visceral leishmaniasis in areas of high transmission. J. Infect. Dis. 186, 1314-1320.

39. Costa-Val, A.P., Cavalcanti, R.R., Gontigo, N.F., Michalik, M.S.M., Alexander, B., Williams, P., Melo, M.N. 2007. Canine visceral leishmaniasis: relationships between clinical status, humoral immune response, haematology and Lutzomyia (Lutzomyia) longipalpis infectivity. Vet. J. 174, 636-643.

40. Michalsky, E.M., Rocha, M.F., da Rocha-Lima, A.C., Franc, a-Silva, J.C., Pires, M.Q., Oliveira, F.S., Pacheco, R.S., dos Santos, S.L., Barata, R.A., Romanha, A.J., Fortes-Dias, C.L., Dias, E.S. 2007.Infectivity of seropositive dogs, showing different clinical forms of leishmaniasis, to Lutzomyialongipalpisphlebotomine sand flies. Vet Parasitol. 147, :67-76.

41. Amorim, I.F.G., Silva, S.M., Figueiredo, M.M., Moura, E.P., Castro, R.S., Lima, T.K.S., Gontijo, N.F., Michalick, M.S.M., Gollob, K.J., Tafuri, W.L. 2011.Toll receptors type-2 and CR3 expression of canine monocytes and its correlation with immunohistochemistry and xenodiagnosis in visceral leishmaniasis. PLoS ONE 6, e27679. 
42. Soares, M.R.A., Mendonc, a, I.L., Bonfim, J.M., Rodrigues, J.A., Wernek, G.L., Costa, C.H.N., 2011. Canine visceral leishmaniasis in Teresina, Brazil: relationship between clinical features and infectivity for sand flies. Acta Trop. 117, 69.

43. Laurenti, M.D., Rossi, C.N., daMatta, L.R., Tomokane, T.Y., Corbett, E.P., Secundino, N.F.C., Pimenta, P.F.P., Marcondes, M. 2013. Asymptomatic dogs are highly competent to transmit Leishmaniainfantumchagasi to the natural vector. Vet. Parasitol.196, 296-300.

44. Mancianti, F., Gramiccia, M., Gradoni, L., Pieri, S. 1988. Studies on canineleishmaniasis control. 1. Evolution of infection of different clinicalforms of canine leishmaniasis following antimonial treatment. Trans. R. Soc. Trop. Med. Hyg. 82, 566-567.

45. Solano-Gallego, L., Baneth, G., 2008. Canine leishmaniosis - a challenging zoonosis. Eur. J. Comp. Anim. Pract. 18, 232-241.

46. Uilenberg, G. 1995. International collaborative research: significance of tick-borne hemoparasitic diseases to world animal health. Vet. Parasitol.57.19-41.

47. Beck, R., Vojta, L., Mrljak, V, Marinculić, A. Beck, A., Živičnjak, T., and Cacciò, S.M. 2009. Diversity of Babesia and Theileria species in symptomatic and asymptomatic dogs in Croatia.International J Parasitol. 39, 843848. doi:10.1016/j.ijpara.2008.12.005.

48. Bennett, S.R., Quinn, R.L., Teleford, S., Rich, D.S., Kulasekera, V., Obeysekera, N., Collure, J., Siriwardana, D., Kirihena, C.D., Fernando, G. 2005. The prevalence and significance of canine erlichiosis in Colombo, Sri Lanka. SL Vet J. 52, 1-8.

49. Frank, J.R., Breitschwerdt, E.B. 1999.A retrospective study of ehrlichiosis in 62 dogs from North Carolina and Virginia. J. Int. Vet.Med. 13,194-201.

50. Kumara, K.A.A.S., Wickramasinghe, S., Kulanayake, S.M.P., et al. 2013. Molecular identification and prevalence of vector-borne infections in dogs from Western Province in Sri Lanka.2nd Annual Conference and Scientific Sessions of Sri Lankan Society for Microbiology (SSM).PGIS, University of Peradeniya.1, 25.

51. Jayathilake, P.S., Dangolla, A., Silva, I.D. 2001. Observations EhrlichiaCanis in imported dogs; Proceedings of Annual Research Sessions, University of Peradeniya.6: 170.

52. Perez, M., Bodor, M., Zhand, C., Xiong, Q., Rikihisa, Y. 2006, Human infection with Ehrlichiacanisaccompanied by clinical signs in Venezuela. Ann. N. Y. Acad. Sci.1078: 110-117.

53. Little, S.E. 2010 Ehrlichiosis and anaplasmosis in Dogs and cats. Vet.Clin.N. Am. Small Anim.Pract.40,1121-40.

54. Rosypal, A.C., Trip, S. Kinlaw, C., Hailemariam, S., Tidwell, R.R., Lindsay.D.S.,Rajapakse, R.P.V.J., Sreekumari, C.,Dubey, J.P. 2010. Surveillance for Antibodies to Leishmania spp. in Dogs From Sri Lanka. J.Parasitol. 96: 230-231.

55. Karunaweera, N.D., Pratlong, F., Siriwardane,H.Y., Ilahamilla, R.L. Dedet, J.P. 2003. Sri Lankan cutaneous leishmaniasis is caused by Leishmania donovani zymodeme MON-37. Trans.R. Soc. Trop. Med. Hyg. 97,380-381.

56. Solano-Gallego, L., Koutinas, A., Miró, G., Cardoso, L., Pennisi, M.G., Ferrer, L., Bourdeau, P., Oliva, G., Baneth, G., 2009.Directions for the diagnosis, clinical staging, treatment and prevention of canine leishmaniasis.Vet. Parasitol. $165,1-18$.

57. Solano-Gallego, L., Miró, G., Koutinas, A., Cardoso, L., Pennisi, M.G., Fer-rer, L., Bourdeau, P., Oliva, G., Baneth, G., The LeishVet Group, 2011.LeishVet guidelines for the practical management of canine leishman-iosis. Parasite Vector. 4, 86.

58. Prasad, K.L., Kondaiah, P.M,. Rayulu, V.C., Srilatha, C.H. 2017. Domestic Dogs as Reservoir Hosts for LeishmaniaDonovani in the Southernmost Western Ghats in India.Acta Trop.171:64-67.

59. Lakshmanan, B., Jose, K.J., George, A., Usha, N.P., Devada, K. 2018. Molecular detection of Hepatozooncanis in dogs from Kerala.J.Parasit. Dis. 42, 287-290.

60. Allen, K.E., Johnson, E.M., Little, S.E. 2011.Hepatozoonspp. infections in the United States.Vet Clin North Am Small AnimPract. 41:1221-1238.

Page 12/20 
61. Dissanaike, A.S., Abeyewickreme, W., Wijesundera, M.D., Weerasooriya, M.V., Ismail, M.M. 1997. Human dirofilariasis caused by Dirofilaria (Nochtiella) repensin Sri Lanka. Parassitologia.39:375-382.

62. Rajapakshe, R.P.A.S., Perera, W.S.R., Ihalamulla, F.R., Weerasena, K.H.,Jayasinghe, S., Sajeewani, H.B.R., Thammitiyagodage, M.G.,Karunaweera, N.D. 2005.Study of dirofilariasis in a selected area in the Western Province. Ceylon Med. J. 50:58-61.

63. WHO (2016) Maldives and Sri Lanka eliminate lymphatic filariasis. World Health Organization https://www.who.int/southeastasia/news/detail/03-06-2016-maldives-and-sri-lanka-eliminate-lymphatic-filariasis (Accessed on December 2020)

64. Figueredo, L.A., Sales, K.G.D.S., Deuster, K., Pollmeier, M., Otranto, D., Dantas-Torres, F. 2017.Exposure to vector-borne pathogens in privately-owned dogs living in different socioeconomic settings in Brazil. Vet. Parasitol. 30, 243:18-23.

65. Patz, A., Graczyk, T.K., Geller, N. 2000.Effects of environmental change on emerging parasitic diseases.Int J Parasitol. 30, 1395-1405.

\section{Tables}

Table 1 Details of the working dogs at the Sri Lanka Air Force (SLAF) n= 173

\begin{tabular}{|c|c|c|c|}
\hline District & $\begin{array}{l}\text { SLAF location } \\
\text { (n) }\end{array}$ & Breeds & Origin (n) \\
\hline Gampaha & $\begin{array}{l}\text { Katunayake } \\
(161)\end{array}$ & $\begin{array}{l}\text { German } \\
\text { Shepherd (21) } \\
\text { Labrador } \\
\text { Retriever (77) } \\
\text { Doberman (36) } \\
\text { English Springer } \\
\text { spaniel (07) } \\
\text { Rhodesian } \\
\text { Ridgeback (10) } \\
\text { Rottweiler (10) }\end{array}$ & $\begin{array}{l}\text { Imported (21); locally bred (59); parents } \\
\text { imported (45); One parent imported (36) }\end{array}$ \\
\hline Anuradhapura & $\begin{array}{l}\text { Anuradhapura } \\
(08)\end{array}$ & $\begin{array}{l}\text { German } \\
\text { Shepherd (03) } \\
\text { Labrador } \\
\text { Retriever (05) }\end{array}$ & parents imported (06); One parent imported (02) \\
\hline Badulla & $\begin{array}{l}\text { Diyathalawa } \\
(04)\end{array}$ & $\begin{array}{l}\text { Labrador } \\
\text { Retriever (04) }\end{array}$ & parents imported (01); Imported (03) \\
\hline
\end{tabular}

Table 2 Prevalence of infection with sex, age and presence of clinical signs among the different dog categories 


\begin{tabular}{lccrr}
\hline Host examined $(\mathrm{n})$ & \multicolumn{4}{c}{ Prevalence $\mathrm{n}(\%)$} \\
\cline { 2 - 5 } & $\begin{array}{c}\text { SLAF* } \\
(\mathrm{n}=173)\end{array}$ & $\begin{array}{c}\text { Free-roaming }(\mathrm{n}=205) \\
\text { Privately owned } \\
(\mathrm{n}=290)\end{array}$ & $\begin{array}{c}\text { Overall } \\
(\mathrm{n}=668)\end{array}$ \\
\hline Males (271) & 10.9 & 7.8 & 10.0 & 9.6 \\
Females (397) & 11.6 & 18.5 & 16.2 & 15.7 \\
Adults (560) & 16.8 & 22.4 & 24.5 & 21.9 \\
Puppies (108) & 5.8 & 3.9 & 1.7 & 3.4 \\
With clinical signs & $23(59.0)$ & $2(3.7)$ & $47(61.8)$ & $72(42.6)$ \\
Without clinical signs & $16(41.0)$ & $52(96.3)$ & $29(38.2)$ & $97(57.4)$ \\
\hline Total & $39(22.5 \%)$ & $54(26.3 \%)$ & $76(26.2 \%)$ & $169(25.3 \%)$ \\
\hline
\end{tabular}

* Sri Lanka Air Force

Table 3 Prevalence of single and mixed infections of haemoparasites among the Sri Lanka Air Force militar! working dogs, free-roaming and owned dogs from 18 districts in Sri Lanka $(n=668)$ 


\begin{tabular}{|c|c|c|c|c|c|}
\hline \multirow[t]{2}{*}{ Parasite species } & \multicolumn{5}{|c|}{ Prevalence n (\%) } \\
\hline & $\begin{array}{l}\text { SLAF* }^{*} \\
(n=173)\end{array}$ & $\begin{array}{l}\text { Free-roaming } \\
\qquad(\mathrm{n}=205)\end{array}$ & $\begin{array}{c}\text { Privately } \\
\text { owned } \\
(\mathrm{n}=290)\end{array}$ & Overa & all $(n=668)$ \\
\hline \multicolumn{6}{|l|}{ Single infections } \\
\hline Babesia gibsoni & $15(8.7)$ & $26(12.7)$ & $40(13.8)$ & & $81(12.1)$ \\
\hline Babesia canis & 0.0 & 0.0 & $1(0.3)$ & & $1(0.1)$ \\
\hline Ehrlichia canis & $13(7.5)$ & $13(6.3)$ & $19(6.6)$ & & $45(6.7)$ \\
\hline Anaplasma platys & $8(4.6)$ & $2(1.0)$ & $4(1.4)$ & & $14(2.1)$ \\
\hline Hepatozoon canis & 0.0 & 0.0 & $1(0.3)$ & & $1(0.1)$ \\
\hline Leishmania sp. & 0.0 & $2(1.0)$ & 0.0 & & $2(0.3)$ \\
\hline Microfilaria & 0.0 & 0.0 & 0.0 & & 0.0 \\
\hline Total (Single) & $36(20.8 \%)$ & $43(21.0 \%)$ & $65(22.4 \%)$ & & $144(21.6 \%)$ \\
\hline \multicolumn{6}{|l|}{ Mixed infections } \\
\hline B. gibsoni + E. canis & 0.00 & $3(1.4)$ & $4(1.3)$ & & $7(1.0)$ \\
\hline B. gibsoni + Microilariae & 0.00 & $1(0.4)$ & $2(0.6)$ & & $3(0.4)$ \\
\hline B. gibsoni + A. platys & 0.00 & $1(0.4)$ & 0.00 & & $1(0.1)$ \\
\hline E. canis $+A$. platys & $2(1.1)$ & $6(2.9)$ & $5(1.7)$ & & $13(1.9)$ \\
\hline \multicolumn{2}{|l|}{ +Microfilariae } & 0.00 & 0.00 & & $1(0.1)$ \\
\hline Total (Mixed) & $3(1.7 \%)$ & $11(5.4 \%)$ & $11(3.8 \%)$ & & $25(3.7 \%)$ \\
\hline \multicolumn{6}{|l|}{ **Overall } \\
\hline Babesia gibsoni & $15(8.7)$ & $31(15.1)$ & & $6(15.9)$ & $92(13.8)$ \\
\hline Babesia canis & - & - & & $1(0.3)$ & $2(0.3)$ \\
\hline Ehrlichia canis & $15(8.7)$ & $22(10.7)$ & & $28(9.7)$ & $65(9.7)$ \\
\hline Anaplasma platys & $11(6.4)$ & $9(4.4)$ & & $9(3.1)$ & $29(4.3)$ \\
\hline Hepatozoon canis & - & - & & $1(0.3)$ & $1(0.1)$ \\
\hline Leishmania sp. & - & $2(1.0)$ & & - & $2(0.3)$ \\
\hline Microfilariae & $1(0.6)$ & $1(0.5)$ & & $2(0.7)$ & $4(0.6)$ \\
\hline Grand total & $2(24.3 \%)$ & $64(31.7 \%)$ & 85( & $(29.3 \%)$ & $195(29.2)$ \\
\hline
\end{tabular}

*. Sri Lanka Air Force ** same dog was counted twice or thrice for mixed infections

Table 4 Distribution of hemoparasites in military dogs in the three Sri Lanka Air Force (SLAF) bases 


\begin{tabular}{lcccccc}
\hline $\begin{array}{l}\text { District } \\
\text { (No. of dogs) }\end{array}$ & \multicolumn{6}{c}{ No. of dogs infected with haemoparasite } \\
\cline { 2 - 7 } & Bg & Ec & Ap & F & Prevalence (\%) \\
\hline Anuradhapura (8) & - & 1 & 2 & - & 33.3 \\
Gampaha (161) & 15 & 13 & 9 & 1 & 23.6 \\
Badulla (4) & - & 1 & - & - & 25.0 \\
\hline Total (173) & $\mathbf{1 5}$ & $\mathbf{1 5}$ & $\mathbf{1 1}$ & $\mathbf{1}$ & $\mathbf{2 4 . 3}$ \\
\hline
\end{tabular}

$\mathrm{Bg}=$ Babesia gibsoni; Ec = Ehrlichia canis; $\mathrm{Ap}=$ Anaplasma platys; $\mathrm{F}=$ Filaria worm

Table 5 Geographic distribution of hemoparasites in free-roaming and privately owned dogs in the 18 districts

\begin{tabular}{|c|c|c|c|c|c|c|c|c|c|c|c|c|c|c|c|c|c|c|c|c|c|c|}
\hline \multirow[b]{2}{*}{ )istrict } & \multicolumn{6}{|c|}{ Free-roaming } & \multicolumn{8}{|c|}{ Owned dogs } & \multicolumn{8}{|c|}{ Overall } \\
\hline & $\mathbf{n}$ & $\mathrm{Bg}$ & Ec & Ap & L F & Total & $\mathbf{n}$ & $\mathrm{Bg}$ & Bc & Ec & Ap & $\mathrm{Hc}$ & $F$ & Total & $\mathbf{n}$ & $\mathrm{Bg}$ & Bc & Ap & Ec & $\mathrm{Hc}$ & L F & F Total \\
\hline radhapura & 5 & 2 & 1 & - & -- & 3 & 10 & 3 & - & 1 & 1 & - & - & 5 & 15 & 5 & - & 1 & 2 & - & - & 8 \\
\hline ipaha & 10 & 3 & 1 & - & 21 & 7 & 5 & 2 & - & - & - & - & 1 & 3 & 15 & 5 & - & - & 1 & - & 22 & 10 \\
\hline .napura & 15 & 2 & 1 & - & - & 3 & 35 & 1 & - & 1 & - & - & - & 2 & 50 & 3 & - & - & 2 & - & - & 5 \\
\hline e & 5 & 1 & 2 & 1 & - & 4 & 10 & 3 & - & 7 & 1 & - & - & 11 & 15 & 4 & - & 2 & 9 & - & - & - 15 \\
\hline mbo & 25 & 3 & 2 & 1 & - & 6 & 40 & 4 & 1 & 2 & - & 1 & - & 8 & 65 & 7 & 1 & 1 & 4 & 1 & - & - 14 \\
\hline thara & 25 & 2 & 7 & 4 & -- & 13 & 40 & 4 & - & 2 & 3 & - & - & 9 & 65 & 6 & - & 7 & 9 & - & - & -22 \\
\hline ale & 40 & 8 & 1 & - & - & 9 & 20 & 4 & - & 3 & - & - & - & 7 & 60 & 12 & 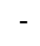 & - & 4 & - & - & 16 \\
\hline uniya & 10 & 1 & - & - & - & 1 & 5 & 1 & - & 1 & - & - & - & 2 & 15 & 2 & - & - & 1 & - & - & 3 \\
\hline ıа & 20 & 1 & 2 & 1 & - & 4 & 20 & 5 & - & 4 & 1 & - & - & 10 & 40 & 6 & - & 2 & 6 & - & - & 14 \\
\hline aitivu & 5 & - & 1 & 1 & - & 2 & 15 & 2 & - & 3 & 1 & - & - & 6 & 20 & 2 & - & 2 & 4 & - & - & 8 \\
\hline ibanthota & 5 & - & 1 & 1 & - & 2 & 10 & 2 & - & 1 & - & - & - & 3 & 15 & 2 & - & 1 & 2 & - & - & 5 \\
\hline dy & 5 & 1 & - & - & - & 1 & 10 & 4 & - & - & - & - & - & 4 & 15 & 5 & - & - & - & - & - & \\
\hline nnaruwa & 5 & 1 & - & - & - & 1 & 10 & 2 & - & - & 1 & - & - & 3 & 15 & 3 & - & 1 & - & - & - & 4 \\
\hline comalee & 5 & 2 & - & - & - & 2 & 10 & & - & - & - & - & - & 0 & 15 & 2 & - & - & - & - & - & 2 \\
\hline ;icaloa & 5 & 1 & 1 & - & - & 2 & 10 & 1 & - & - & - & - & - & 1 & 15 & 2 & - & - & 1 & - & - & 3 \\
\hline lam & 10 & 1 & - & - & - & 1 & 20 & 3 & - & 3 & - & - & - & 6 & 30 & 4 & - & - & 3 & - & - - & 7 \\
\hline unegala & 5 & - & 1 & - & - & 1 & 10 & 2 & - & 1 & - & - & - & 3 & 15 & 2 & - & - & 2 & - & - - & 4 \\
\hline ara & 5 & 1 & - & - & - & 1 & 10 & 2 & - & - & - & - & - & 2 & 15 & 3 & - & - & - & - & - & 3 \\
\hline & 205 & & 21 & 9 & 21 & 63 & 290 & 45 & 1 & 29 & 8 & 1 & 1 & 85 & 495 & 75 & & & 50 & 1 & & 2148 \\
\hline
\end{tabular}

* Prevalence of infections in free-roaming and privately owned dogs; $\mathrm{n}=$ number of dogs sampled; $\mathrm{Bg}$ = Babesia gibsoni, $\mathrm{Bc}=$ Babesia canis, $\mathrm{Ec}=$ Ehrlichia canis, $\mathrm{Ap}=$ Anaplasma platys $\mathrm{F}=$ Microfilaria, $\mathrm{L}=$ Leishmani

Table 6 Breed of the dogs and the haemoprarasites in the blood samples collected from the Sri Lanka Air Force military working dogs, free-roaming and privately owned dogs from 18 districts in Sri Lanka 


\begin{tabular}{|c|c|c|c|c|c|c|c|c|c|c|c|c|}
\hline & \multicolumn{3}{|c|}{ SLAF (\%) } & \multicolumn{3}{|c|}{ Free roaming (\%) } & \multicolumn{3}{|c|}{ Privately owned (\%) } & \multicolumn{3}{|c|}{ Overall (\%) } \\
\hline & Total & Single & Mixed & Total & Single & Mixed & Total & Single & Mixed & Total & Single & Mixed \\
\hline \multicolumn{13}{|l|}{ man } \\
\hline & $2(1.7)$ & $1(2.8)$ & $1(2.8)$ & - & - & - & $4(16.0)$ & $4(16.0)$ & 0.0 & $6(9.8)$ & $5(8.2)$ & $1(1.6)$ \\
\hline \multicolumn{13}{|l|}{ erd } \\
\hline \multicolumn{13}{|l|}{ dor } \\
\hline & $23(25.1)$ & $21(24.4)$ & $1(1.2)$ & \multicolumn{9}{|c|}{ ver } \\
\hline \multicolumn{13}{|l|}{ hund } \\
\hline & - & - & - & - & - & - & $5(83.3)$ & $5(83.3)$ & 0.0 & $5(83.3)$ & $5(83.3)$ & 0 \\
\hline $3(7)$ & - & - & - & - & - & - & $7(100)$ & $5(71.4)$ & $2(28.6)$ & $7(100)$ & $5(71.4)$ & $2(28.6)$ \\
\hline \multicolumn{13}{|l|}{ anian } \\
\hline \multirow{2}{*}{\multicolumn{13}{|c|}{$\begin{array}{l}\text { sian } \\
\text { Jack }\end{array}$}} \\
\hline & & & & & & & & & & & & \\
\hline & 10 & 0.0 & 0.0 & - & - & - & 11(61.1) & $9(50.0)$ & $(11.1)$ & 11(39.3) & $9(32.1)$ & $2(7.1)$ \\
\hline$r(5)$ & - & - & - & - & - & - & $1(20.0)$ & $1(20.0)$ & 0.0 & 1(20.0) & $1(20)$ & 0 \\
\hline (6) & - & - & - & - & - & - & $2(33.3)$ & $2(33.3)$ & 0.0 & $2(33.3)$ & $2(33.3)$ & 0 \\
\hline zu (3) & - & - & - & - & - & - & $3(100)$ & $3(100)$ & 0.0 & $3(100)$ & $3(100)$ & 0 \\
\hline \multicolumn{13}{|l|}{$\mathrm{r}$} \\
\hline Iniel & - & - & - & - & - & - & $3(33.3$ & $3(33.3$ & 0.0 & $3(33.3)$ & $3(33.3)$ & 0 \\
\hline \multicolumn{13}{|l|}{ istiff } \\
\hline \multicolumn{13}{|l|}{$\begin{array}{l}\text { h } \\
\text { l (7) }\end{array}$} \\
\hline & $2(28.6)$ & $2(28.6)$ & 0.0 & - & - & - & - & - & - & $2(28.6)$ & $2(28.6)$ & 0 \\
\hline \multicolumn{13}{|l|}{ in } \\
\hline erd & & & & & & & & & 1 & & & \\
\hline$(2)$ & - & - & - & - & - & - & $1(50.0)$ & 0.0 & $(50.0)$ & $1(50.0)$ & 0 & $1(50.0)$ \\
\hline \multicolumn{13}{|l|}{$\operatorname{man}$} \\
\hline (2) & - & - & - & - & - & - & $1(50.0)$ & $1(50.0)$ & 0.0 & $1(50.0)$ & $1(50.0)$ & 0 \\
\hline \multicolumn{13}{|l|}{ cross } \\
\hline & - & - & - & - & - & - & $1(100)$ & 0.0 & $1(100)$ & $1(100)$ & 0 & $1(100)$ \\
\hline \multicolumn{13}{|l|}{ eiler } \\
\hline & 10 & 0.0 & 0.0 & - & - & - & 0.0 & 0.0 & 0.0 & 0.0 & 0 & 0 \\
\hline \multicolumn{13}{|l|}{ el } \\
\hline & - & - & - & 205 & $43(20.1)$ & $11(5.4)$ & $7(8.3)$ & $5(5.9)$ & $2(2.4)$ & $61(21.1)$ & $48(16.6)$ & $13(4.5)$ \\
\hline \multirow[t]{2}{*}{ ) } & - & - & - & - & - & - & 0.0 & 0.0 & 0.0 & 0.0 & 0 & 0 \\
\hline & $39(22.5)$ & $36(20.8)$ & $3(1.7)$ & $54(21.5)$ & $43(20.9)$ & 11(5.4) & $76(26.2)$ & $\begin{array}{r}66 \\
(22.8)\end{array}$ & $\begin{array}{r}10 \\
(3.5)\end{array}$ & 169 & $145(21.7)$ & $24(3.6)$ \\
\hline
\end{tabular}

Table 7 Clinical signs of the dog breeds/categories sampled from 18 districts in Sri Lanka 


\begin{tabular}{llrl}
\hline $\begin{array}{l}\text { Dog category } \\
(\mathbf{n})\end{array}$ & $\begin{array}{l}\text { Pedigree or } \\
\text { breed }\end{array}$ & $\begin{array}{c}\text { No. of dogs with } \\
\text { clinical } \\
\text { signs }\end{array}$ & \multicolumn{1}{c}{$\begin{array}{c}\text { Types of clinical } \\
\text { signs }\end{array}$} \\
\hline SLAF (30) & Doberman & 3 & Anorexia, lethargy \\
& German Shepherd & 7 & fever, pale mucosa, \\
& Labrador Retriever & 17 & sark urine, epistaxis, \\
skin bleeding on ventral abdomen, \\
& English Spaniel & 3 & emaciation \\
\hline Free-roaming & Mongrels or Sinhalese & 2 & Skin wounds \\
$(2)$ & hound type & & \\
\hline Privately owned & Doberman & 1 & Anorexia, lethargy \\
$(53)$ & German Shepherd & 2 & Fever, pale mucosa, \\
& Labrador Retriever & 17 & dark urine, epistaxis, \\
& Dachshund & 5 & skin bleeding on ventral abdomen, \\
& Beagle & 4 & emaciation \\
& Pomeranian & 6 & \\
& Rhodesian Ridgeback & 6 & \\
& Terrier & 1 & \\
& Boxer & 3 & \\
& Shih tzu & 3 & \\
& Cocker Spaniel & 3 & \\
& Bullmatiff & 2 & \\
\hline
\end{tabular}

Table 8 Dogs infected with haemoparasites having clinical signs and no clinical signs among the Sri Lanka Air Force military working dogs, free-roaming and privately owned dogs from 18 districts in Sri Lanka 


\begin{tabular}{|c|c|c|c|c|c|c|}
\hline \multirow[t]{3}{*}{ Species of parasite } & \multicolumn{6}{|c|}{$\begin{array}{l}\text { Number of dogs infected with no clinical signs /infected with clinical } \\
\text { signs }\end{array}$} \\
\hline & \multirow[t]{2}{*}{ SLAF } & \multicolumn{2}{|c|}{ Free-roaming } & \multicolumn{2}{|c|}{ Privately owned } & \multirow[t]{2}{*}{ Total } \\
\hline & & $\begin{array}{l}\text { Near } \\
\text { SLAF }\end{array}$ & Vet Clinics & Near SLAF & Vet Clinics & \\
\hline \multicolumn{7}{|l|}{ Single infections } \\
\hline Babesia gibsoni & $7 / 8$ & $14 / 0$ & $12 / 0$ & $8 / 0$ & $3 / 29$ & $44 / 37$ \\
\hline Babesia canis & $0 / 0$ & $0 / 0$ & $0 / 0$ & $0 / 0$ & $0 / 1$ & $0 / 1$ \\
\hline Ehrlichia canis & $4 / 9$ & $9 / 0$ & $4 / 0$ & $5 / 0$ & $3 / 11$ & $25 / 20$ \\
\hline Anaplasma platys & $5 / 3$ & $2 / 0$ & $0 / 0$ & $1 / 0$ & $1 / 2$ & $9 / 5$ \\
\hline Hepatozoon canis & $0 / 0$ & $0 / 0$ & $0 / 0$ & $0 / 0$ & $0 / 1$ & $0 / 1$ \\
\hline Leishmania sp. & $0 / 0$ & $0 / 2$ & $0 / 0$ & $0 / 0$ & $0 / 0$ & $0 / 2$ \\
\hline Total & $16 / 20$ & $25 / 2$ & $16 / 0$ & $14 / 0$ & $7 / 44$ & $78 / 66$ \\
\hline \multicolumn{7}{|l|}{ Mixed infections } \\
\hline B. gibsoni + E. canis & $0 / 0$ & $3 / 0$ & $0 / 0$ & $0 / 0$ & $1 / 3$ & $4 / 3$ \\
\hline B. gibsoni + Microfilariae & $0 / 0$ & $1 / 0$ & $0 / 0$ & $2 / 0$ & $0 / 0$ & $3 / 0$ \\
\hline B. gibsoni $+A$. platys & $0 / 0$ & $1 / 0$ & $0 / 0$ & $0 / 0$ & $0 / 0$ & $1 / 0$ \\
\hline E. canis $+A$. platys & $0 / 2$ & $6 / 0$ & $0 / 0$ & $3 / 0$ & $2 / 0$ & $11 / 2$ \\
\hline B. canis $+A$. platys & $0 / 1$ & $0 / 0$ & $0 / 0$ & $0 / 0$ & $0 / 0$ & $0 / 1$ \\
\hline \multicolumn{7}{|l|}{ + Mirofilariae } \\
\hline Total & $0 / 3$ & $11 / 0$ & $0 / 0$ & $5 / 0$ & $3 / 3$ & $19 / 6$ \\
\hline Grand Total & $16 / 23$ & $36 / 2$ & $16 / 0$ & $19 / 0$ & $10 / 47$ & $97 / 72$ \\
\hline
\end{tabular}

\section{Figures}




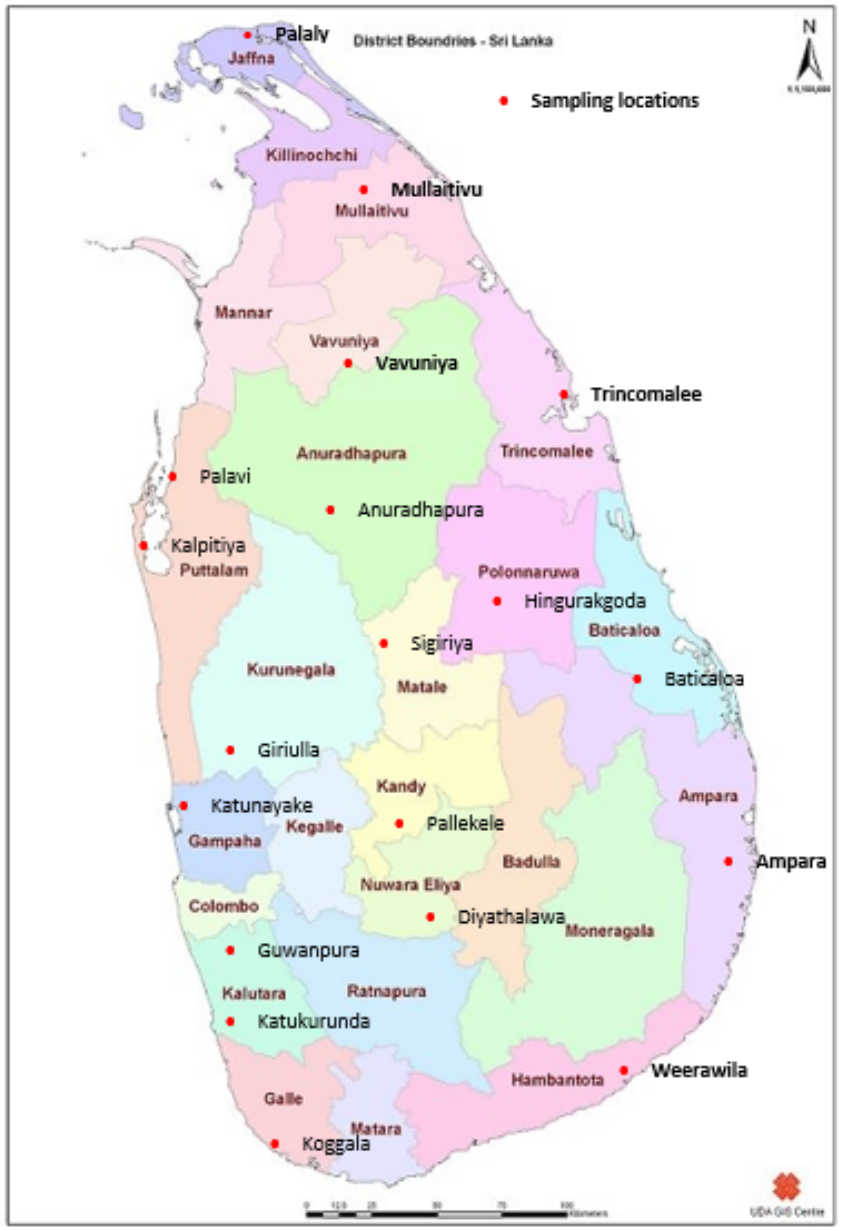

\section{Figure 1}

Blood samples from dogs were collected from 18 districts (out of 25) in Sri Lanka

\section{Supplementary Files}

This is a list of supplementary files associated with this preprint. Click to download.

- Graphicalabstract.doc 